Revue bibliographique pour le domaine irano-aryen

\title{
Ehsan Shavarebi. „Sakastān in der frühen Sasanidenzeit: Münzprägung und Geschichte“
}

\section{Rika Gyselen}

\section{(2) OpenEdition \\ 12 Journals}

\section{Édition électronique}

URL : http://journals.openedition.org/abstractairanica/49646

DOI : 10.4000/abstractairanica.49646

ISBN : 1961-960X

ISSN : 1961-960X

Éditeur :

CNRS (UMR 7528 Mondes iraniens et indiens), Éditions de l'IFRI

Référence électronique

Rika Gyselen, «Ehsan Shavarebi. „Sakastān in der frühen Sasanidenzeit: Münzprägung und

Geschichte" », Abstracta Iranica [En ligne], Volume 40-41 | 2019, document 26, mis en ligne le 30 octobre 2019, consulté le 19 avril 2021. URL : http://journals.openedition.org/abstractairanica/49646 DOI : https://doi.org/10.4000/abstractairanica.49646

Ce document a été généré automatiquement le 19 avril 2021.

Tous droits réservés 


\title{
Ehsan Shavarebi. „Sakastān in der frühen Sasanidenzeit: Münzprägung und Geschichte"
}

\author{
Rika Gyselen
}

\section{RÉFÉRENCE}

Ehsan Shavarebi. „Sakastān in der frühen Sasanidenzeit: Münzprägung und Geschichte“ in Marek Jan Olbrycht (ed.). Collectanea Iranica et Asiatica. Iran and Western Asia in Antiquity. New Perspectives (Anabasis 8), 2017, p. 160-177

1 L'A. discute une série monétaire qui a déjà fait couler beaucoup d'encre dans la littérature numismatique. Sur l'avers figurent un grand et un petit buste entourés d'une inscription dont la partie à droite n'avait pas pu être lue. Les personnages ont été traditionnellement identifiés comme le roi Ardašīi Ier et le prince héritier Šābuhr. Dès 2003, M. Alram avait suggéré que le petit buste devrait être celui du vice-roi Ardašīi $\overline{1}$ Sakān-šāh "Ardašīr, roi de Sakas » (SNS I, 2003, où on trouvera aussi toute l'argumentation qui a permis d'attribuer cette série, en argent et en cuivre, à un atelier monétaire situé dans l'ancien royaume indo-parthe dont le Sakastān compose une partie). Depuis sont apparues des monnaies qui ont permis de lire la légende à droite, qui est rétrograde, comme "Ardasīr ì Sakān-sāh», personnage mentionné dans la grande inscription de Šābuhr Ier sur la Ka'ba de Zoroastre (ŠKZ §41) (N. Schindel, «A new look at the Thronfolgerprägungen of the Sasanian king Ardashir: Goodbye to Shapur I, welcome to Ardashir Sakanshah ", The Numismatic Chronicle, 179, 2016, p. 227-240, pl. 27). L'identification proposée par l'A pour le petit buste comme celui d'Abarsām (également mentionné dans ŠKZ §42) est contredite par la légende (reconstitution graphique dans Gyselen, La Géographie administrative de l'empire sassanide. Les témoignages épigraphiques en moyen-perse, Bures-sur-Yvette, 2019, p. 186). 
2 Le fait que plusieurs monnaies de cuivre de cette série furent surfrappées par Šābuhr Ier (p. 168) semble être un argument pour l'A de considérer qu'il ne peut pas s'agir du Sakān-šāh «le roi des Sakas » (voir ResOr 2019). Mais de nombreuses raisons d'ordre politique ont pu être à l'origine de ce geste de Šābuhr Ier. En outre ce n'est pas non plus la seule série monétaire dans laquelle est figuré et mentionné un vice-roi. Sur le revers de quelques drahm de Yazdgerd Ier figure Šābuhr ì wuzurg armenān šāh, son fils Šābuhr qui était le grand roi de Arméniens (N. Schindel, Sylloge Nummorum Sasanidarum. The Schaaf Collection, Wien, Österreichische Akademie der Wissenschaften, 2014 [pour une reconstruction graphique : Gyselen, op.cit., p. 44]). En revanche, jusqu'à présent aucune monnaie sassanide ne porte l'effigie d'un ministre.

\section{AUTEURS}

\section{RIKA GYSELEN}

CNRS, Mondes iranien et indien 